\title{
Bmp4 expressed in preadipocytes is required for the onset of adipocyte differentiation
}

\section{AUTHOR(S):}

Suenaga, Masashi; Kurosawa, Norio; Asano, Hiroki; Kanamori, Yohei; Umemoto, Takenao; Yoshida, Hirofumi; Murakami, Masaru; Kawachi, Hiroyuki; Matsui, Tohru; Funaba, Masayuki

\section{CITATION:}

Suenaga, Masashi ...[et al]. Bmp4 expressed in preadipocytes is required for the onset of adipocyte differentiation. Cytokine 2013, 64(1): 138-145

\section{ISSUE DATE:}

2013-10

URL:

http://hdl.handle.net/2433/178733

\section{RIGHT:}

@ 2013 Elsevier Ltd.; この論文は出版社版でありません。引用の際には 出版社版をご確認ご利用ください。; This is not the published version. Please cite only the published version. 
Bmp4 expressed in preadipocytes is required for the onset of adipocyte differentiation

Masashi Suenaga $^{1}$, Norio Kurosawa ${ }^{1}$, Hiroki Asano ${ }^{1}$, Yohei Kanamori ${ }^{1}$, Takenao Umemoto ${ }^{1}$, Hirofumi Yoshida ${ }^{1}$, Masaru Murakami ${ }^{2}$, Hiroyuki Kawachi ${ }^{1,3}$, Tohru Matsui ${ }^{1}$ and Masayuki Funaba ${ }^{1 *}$

${ }^{1}$ Division of Applied Biosciences, Kyoto University Graduate School of Agriculture, Kyoto 606-8502, Japan

${ }^{2}$ Laboratory of Molecular Biology, Azabu University School of Veterinary Medicine, Sagamihara 229-5201, Japan

${ }^{3}$ Present address: Department of Animal Bioscience, Faculty of Bioscience, Nagahama Institute of Bio-Science and Technology, Nagahama 526-0829, Japan

*Corresponding author: Masayuki Funaba, Ph.D.

Division of Applied Biosciences

Kyoto University Graduate School of Agriculture

Kitashirakawa Oiwakecho, Kyoto 606-8502, Japan

Tel.: +81-75-753-6055

Fax: +81-75-753-6344

E-mail: mfunaba@kais.kyoto-u.ac.jp 


\section{Abstract}

We previously revealed that endogenous bone morphogenetic protein (Bmp) activity is required for lipid accumulation in 3T3-L1 adipocytes. The present study characterized the role of endogenous Bmp activity in preadipocytes. Endogenous Bmp activity was monitored by analyzing the level of phosphorylation of Smad1/5/8, downstream molecules in the Bmp pathway. Higher levels of phosphorylated Smad1/5/8 were detected in adipogenic cells but not in non-adipogenic cells prior to differentiation induction. The inhibition of the Bmp pathway during this period decreased the expression of Ppary2 and C/ebpo, which are transcription factors responsible for adipocyte differentiation. The expression of these transcription factors were also down-regulated by Bmp4 knockdown. In addition, endogenous Bmp4 was required for the repression of Intrleukin-11 expression. Endogenous Bmp4 in preadipocytes is indispensable for the onset of the adipogenic program, and may help to maintain the preadipocytic state during adipocyte differentiation.

Keywords: Bmp4, adipocyte differentiation, preadipocytes, Interleukin-11 


\section{Introduction}

In addition to its role as the major energy-storage tissue, adipose tissue integrates a wide array of homeostatic processes by secreting various cytokines. Because excess and deficient levels body fat are related to various (patho-)physiological conditions, optimal body fat mass is essential for the maintenance of health [1]. The amount of adipose tissue is determined by the size and number of adipocytes. Adipocyte size largely reflects the amount of stored triglycerides, whereas adipocyte number is regulated by the commitment of mesenchymal stem cells in the adipocyte lineage and by the proliferation and differentiation of preadipocytes. Peroxisome proliferator-activated receptor $\gamma$ (Ppary), a nuclear hormone receptor, is the dominant regulator for adipocyte differentiation, and various molecules including growth factors and hormones affect adipogenesis through the modulation of Ppary expression and activity [2].

Bone morphogenetic proteins (Bmps), members of the transforming growth factor- $\beta$ (Tgf- $\beta$ ) family, regulate diverse physiological processes including adipose tissue formation [3]. The role of Bmps in the commitment of pluripotent stem cells to the adipocyte lineage (adipocyte progenitors) has been well established [4]. The addition of Bmp4 to the culture medium stimulated the adipocyte differentiation of multipotential C3H10T1/2 cells [5, 6] and mouse embryonic fibroblasts [7]. A33 cells, a subline of C3H10T1/2 cells treated with the DNA methylation inhibitor 5-azacytidine, were committed to the adipocyte lineage and highly expressed and secreted Bmp4 [8]. In contrast, the roles of Bmps in the differentiation of preadipocytes into adipocytes are controversial; treatment with Bmp2 decreased insulin-induced lipid accumulation in 3T3-F442A preadipocytes [9], whereas Bmp7 stimulated the adipocyte differentiation of 3T3-L1 preadipocytes [10].

3T3-L1 preadipocytes are frequently used as a cell model for adipocyte differentiation. In a standard differentiation program, growth-arrested confluent 3T3-L1 preadipocytes are treated with the appropriate hormonal agents, which induce synchronous reentrance into the cell cycle and undergo at least 2 rounds of mitosis, referred to as mitotic clonal expansion. Subsequently, the preadipocytes exit the cell cycle and begin to differentiate into adipocytes [11]. We previously analyzed endogenous Bmp activity during the adipocyte differentiation of 3T3-L1 preadipocytes; Bmp activity was higher before differentiation induction, and the inhibition of this activity decreased lipid accumulation [12]. These results suggest a novel activity of Bmp in preadipocytes, but the following points remained to be clarified: 1) the levels of endogenous Bmp activity in the other 
adipogenic and non-adipogenic cells, 2) the effects of exogenous Bmp after differentiation induction in 3T3-L1 cells, 3) the identities of the molecule(s) responsible for the higher Bmp activity prior to differentiation induction in 3T3-L1 cells, and 4) the possible target process(es) involved in the progression of the adipogenic program. In this study, we explored these unknowns to understand the precise role of Bmp during adipogenesis.

\section{Materials and methods}

\subsection{Materials}

The following reagents were purchased: dorsomorphin (compound $\mathrm{C}$ : 6-[4-(2-piperidin-1-yl-ethoxy)phenyl]-3-pyridin-4-yl-pyrazolo[1,5-a] pyrimidine) was from Calbiochem (La Jolla, CA, USA); LDN-193189 was from Stemgent (San Diego, CA, USA); purified Tgf- $\beta 1$ was from Becton Dickinson (Franklin Lakes, NJ, USA); recombinant Activin A, Bmp2 and Bmp4 were from R \& D Systems (Minneapolis, MN, USA); rabbit polyclonal antibody against phospho-Smad1 (Ser463/Ser465)/Smad5 (Ser463/Ser465)/Smad8 (Ser426/Ser428) (\#9511) and rabbit polyclonal antibody against phospho-Smad2 (Ser465/Ser467) were from Cell Signaling Technology (Danvers, MA, USA); and rabbit monoclonal antibody against Smad1 (ab33902), rabbit polyclonal antibody against Smad2 (ab63576), and mouse monoclonal antibody against and $\beta$-actin (AC-15) were from Abcam (Cambridge, MA, USA).

\subsection{Cell culture}

3T3-L1 preadipocytes were cultured and differentiated as described previously [12]. Bovine stromal-vascular (SV) cells were isolated from perirenal adipose tissues as follows. The tissues from 28- to 32-month-old Japanese Black steers were digested by with type I collagenase $(1 \mathrm{mg} / \mathrm{ml})$ in Hank's balanced salt solution containing penicillin $(100 \mathrm{U} / \mathrm{ml})$, streptomycin $(100 \mu \mathrm{g} / \mathrm{ml})$ and amphotericin B $(250 \mathrm{ng} / \mathrm{ml})$ and subsequently filtered through a $250 \mu \mathrm{m}$ nylon mesh filter to remove undigested tissue fragments and debris. After centrifugation, the cell pellet consisting of SV cells containing preadipocytes was washed with growth medium, i.e., Dulbecco's modified Eagle's medium (DMEM) containing 10\% FBS, ascorbic acid phosphate magnesium salt $(100 \mu \mathrm{M})$ and antibiotics, followed by resuspension in the growth medium containing 10\% DMSO and storage in liquid nitrogen. The adipocyte differentiation of the SV cells was induced as described previously [13]. Two days after reaching confluence (day 0), cells were cultured in the growth medium in the presence of 
differentiation inducers (3-isobutyl-1-methylxanthine $(0.5 \mathrm{mM})$, dexamethasone $(0.25 \mu \mathrm{M})$ and insulin $(10 \mu \mathrm{g} / \mathrm{ml}))$ for 2 days, followed by culture with insulin $(5 \mu \mathrm{g} / \mathrm{ml})$ in the growth medium. To investigate the effects of dorsomorphin and LDN-193189 on adipocyte differentiation, dorsomorphin $(10 \mu \mathrm{M})$ or LDN-193189 $(100 \mathrm{nM})$ dissolved in DMSO was added to the culture medium for the indicated period; treatments with the concentration of the inhibitors effectively blocked Bmp-induced phosphorylation of Smad1 and transcriptional activation of a Bmp-responsive gene Id1 [14, 15]. An equal concentration of DMSO (0.1\%) was used as a control. Lipid accumulation was examined by Oil Red $\mathrm{O}$ staining on day 8 . The images were obtained by scanning stained wells (GT-9400UF; EPSON, Tokyo, Japan). Subsequently, dye was extracted with 2-propanol. The absorbance of the solution was measured at $510 \mathrm{~nm}$ for quantification [12].

\subsection{Western blotting}

To examine changes in phosphorylated Smad1/5/8 expression over time, cells were recovered in $200 \mathrm{mM}$ phosphate buffer, $\mathrm{pH}$ 7.4, $2 \mathrm{M} \mathrm{NaCl}, 2 \mathrm{mM} \mathrm{Na} 3 \mathrm{VO}_{4}, 1 \mathrm{mM}$ PMSF and $1 \%$ aprotinin and then lysed by ultrasonication. DNA content was measured by the method of Labarca and Paigen [16]. Samples containing equal amounts of DNA were subjected to SDS-PAGE, followed by immunoblotting as described previously [17]. The reacted proteins were visualized using the ECL Plus Western Blotting Detection System (GE Healthcare) according to the manufacturer's protocol. After stripping the antibodies and the detection reagents, the membranes were reprobed with anti-Smad 1 antibody or anti- $\beta$-actin antibody.

To examine effects of protein kinase inhibitors on ligand-induced Smad phosphorylation, cells were cultured in medium with $0.2 \%$ FBS for $4 \mathrm{~h}$, treated with vehicle (DMSO), dorsomorphin $(5 \mu \mathrm{M})$ or LDN-193189 (100 nM) with $0.2 \%$ FBS for $20 \mathrm{~min}$, and subsequently stimulated with Tgf- $\beta 1$ (200 pM), Activin A (4 nM) or Bmp2 (4 nM) in the presence of the kinase inhibitor for $1 \mathrm{~h}$.

\section{4. $R T-q P C R$}

RNA isolation and RT-qPCR were performed as described previously [12]. The oligonucleotide primers for RT-qPCR are presented in Table 1. The $\mathrm{C}_{t}$ value was determined, and the abundances of gene transcripts were calculated from the $C_{t}$ value using Hprt1 as the normalization gene. 


\subsection{Double-stranded RNA transfection}

Double-stranded RNAs (dsRNAs) targeting the expression of Bmp4 and green fluorescent protein (GFP) were synthesized by BONAC corporation (Kurume, Japan). The coding sequence of the dsRNA for GFP is as described previously [16]. Four oligonucleotides were designed

5'-GUUGAAAAAUUAUCAGGAGAU-3' to target Bmp4,

5'-CUCCUGAUAAUUUUUCAACAC-3'

(set (set 1), 5'-CAGACUAGUCCAUCACAAUGU-3' (set 1) and 5'-AUUGUGAUGGaCUAGUCUGGU-3' (set 2). To make dsRNA, the two oligonucleotides of each set were mixed, and 1:1 mixtures of the dsRNA were prepared. dsRNA transfection was performed using the Lipofectamine RNAiMAX regent (Invitrogen: Carlsbad, CA, USA) according to the manufacturer's protocol.

\subsection{Plasmids and reporter assay}

BRE-luc was kindly provided by Dr. P. ten Dijke. The other reporter genes were constructed by a PCR-based method, and all constructs were verified by DNA sequencing. Luciferase-based reporter assays were conducted as described previously [18]. 3T3-L1 cells were transiently transfected with the indicated firefly luciferase-based reporter construct using Lipofectamine LTX reagent (Invitrogen). A Renilla reniformis luciferase vector driven by the thymidine kinase promoter (Renilla-luc; Promega, Madison, WI, USA) was co-transfected to serve as an internal control for transfection efficiency. At $24 \mathrm{~h}$ after transfection, the cells were treated with Bmp4 (4 nM) for $16 \mathrm{~h}$. Firefly luciferase activity was normalized to Renilla luciferase activity, and the luciferase activity in the cell lysate in the absence of ligand was set to 1.

\subsection{Statistical analyses}

Data are expressed as the mean \pm SEM. Differences between treatments were examined by Student's $t$-test. Differences of $P<0.05$ were considered significant.

\section{Results and discussion}

Bmp transmits signals through the phosphorylation of Smad1/5/8 at the C-terminus after complex formation with ligand, type I receptors and type II receptors [19, 20]. Phosphorylated Smad1/5/8 levels were monitored to evaluate endogenous Bmp activity during adipocyte differentiation (Fig. 1). Consistent with a previous study [12], the 
intensity of the bands was higher for 3T3-L1 preadipocytes on day -2 (lane 1) and gradually decreased with the progression of differentiation (lanes 2-8). NIH-3T3 cells did not significantly differentiate into cells with lipid droplets, even if cells were treated using the differentiation protocol for 3T3-L1 cells (data not shown). Unlike 3T3-L1 cells, NIH-3T3 cells did not exhibit higher levels of phosphorylated Smad1/5/8 expression prior to treatment with differentiation inducers (Fig. 1, lane 9), although the expression levels on days 1, 2 and 10 were relatively higher (lanes 11, 12 and 16).

We next evaluated time-course changes in expression of Bmp receptors during adipogenesis in 3T3-L1 cells (Fig. 2). Alk2, Alk3 and Alk6 are type I receptors for Bmp, whereas Actr2a, Actr2b and Bmpr2 function as type II receptors for Bmp [19, 20]. No significant expression of Alk6 was detected throughout the adipogenesis of 3T3-L1 cells (data not shown). Expression level of all the Bmp receptors, except for Actr $2 b$, tended to increase from day -4 to day 0 , and decrease in response to the differentiation stimulation. Thereafter, the decreased level continued at least to day 8. Actr $2 b$ expression tended to increase day -4 to day -1 , and increase again from day 6 to day 8 . Changes in Bmp receptor expression during adipogenesis suggest that responsiveness to Bmp changes before and after the differentiation stimulation, i.e., higher responsiveness to Bmp just before the differentiation stimulation and lower after the stimulation.

Dorsomorphin was identified as an inhibitor of the Bmp pathway by screening for compounds that disrupt dorsoventral axis formation, which is governed by Bmp, in zebrafish [14]. Subsequently, LDN-193189 was synthesized as a structurally related compound capable of efficiently inhibiting Bmp4-induced Smad1/5/8 phosphorylation in murine pulmonary artery smooth muscle cells [21]. To examine the ability of the compounds to inhibit Bmp signaling in 3T3-L1 cells, ligand-induced Smad phosphorylation (Fig. 3A) and Bmp-mediated transcriptional activation (Fig. 3B) were evaluated. Pretreatment with dorsomorphin or LDN-193189 effectively inhibited the Bmp2-induced phosphorylation of Smad1/5/8 (Fig. 3A, upper panel, lanes 4, 8 and 12). As in the other cell types [18, 22-25], treatment of 3T3-L1 cells with Tgf- $\beta 1$ induced the phosphorylation of Smad1/5/8 (Fig. 3A, upper panel, lanes 1 and 2), which was also partially inhibited by pretreatment with dorsomorphin but not with LDN-193189 (Fig. $3 \mathrm{~A}$, upper panel, lanes 6 and 10). The phosphorylation and activation of Smad2 is a canonical Tgf- $\beta 1$ and Activin A pathway [19]. Dorsomorphin and LDN-193189 did not affect the Tgf- $\beta$ 1- or Activin A-induced phosphorylation of Smad2 (Fig. 3A, third panel, lanes 2, 3, 6, 7, 10 and 11). Luciferase-based reporter assays also showed that both 
dorsomorphin and LDN-193189 effectively blocked Bmp4-induced expression of BRE-luc, a sensitive Bmp-responsive reporter gene [26] (Fig. 3B). These results indicate that dorsomorphin and LDN-193189 selectively inhibit Bmp-induced phosphorylation of Smad1/5/8 in 3T3-L1 cells.

To examine the role of the high Bmp activity in preadipocytes, 3T3-L1 cells were treated with dorsomorphin or LDN-193189 before differentiation induction, i.e., from day -2 to day 0 , and lipid accumulation was evaluated on day 8. Although LDN-193189 was less effective, both inhibitors inhibited lipid accumulation, as demonstrated by lower lipid levels on day 8 (Fig. 3C). The reason of the less potency of LDN-193189 on lipid accumulation, irrespective of compatible inhibition of Bmp4-mediated transcriptional activation between dorsomorphin and LDN-193189, is currently unknown. Dorsomorphin inhibits not only the Bmp pathway but also the AMPK pathway; dorsomorphin, also known as compound $\mathrm{C}$, is originally identified as the AMPK inhibitor [27]. It is possible that the AMPK activity is involved in lipid accumulation of 3T3-L1 cells; endogenous AMPK activity was detected in 3T3-L1 preadipocytes [12]. Whatever the reason may be, these results definitely suggest that the high Bmp activity in preadipocytes is necessary for lipid accumulation. Alternatively, decreasing Bmp activity in response to differentiation induction may be required for efficient lipid accumulation. Thus, the effects of additional Bmp on lipid accumulation were examined in 3T3-L1 cells (Fig. 4). Bmp2 was added to the culture medium for various periods of time (Fig. 4A), and lipid accumulation was evaluated by Oil Red O staining on day 8. The presence of additional Bmp2 after differentiation induction did not affect lipid accumulation in 3T3-L1 cells (Fig. 4B). As described above, the inconsistent results have been reported on the role of exogenous Bmps in adipogenesis $[9,10]$. The precise reason of the results is unknown; the discrepancy may relate to subtle differences in cell systems or culture conditions.

The role of endogenous Bmp activity in adipogenic cells other than 3T3-L1 cells was next evaluated. Bovine SV cells can be differentiated into adipocytes in response to treatment with the differentiation inducers used on 3T3-L1 cells [13]. Endogenous Bmp activity was relatively constant during the adipocyte differentiation of SV cells (Fig. 5A). As in 3T3-L1 cells, treatment with dorsomorphin prior to differentiation induction but not after differentiation induction decreased lipid accumulation in SV cells (Fig. 5B and $\mathrm{C}$ ). All of these results suggest that endogenous Bmp activity before differentiation induction is necessary for lipid accumulation during the adipogenic program. 
To identify the process that endogenous Bmp activity regulates, we next examined the expression of genes regulating adipocyte differentiation. Ppary, a dominant and essential regulator of adipocyte differentiation [28-30], controls the transcriptional pathway of adipogenesis in concert with CCAAT/enhancer-binding protein $\alpha(\mathrm{C} / \mathrm{ebp} \alpha)$ [31]. The inhibition of endogenous Bmp activity down-regulated the expression of Ppar 22 and Clebp $\alpha$ (Fig. 6A and B). Consistent with these results, the expression of Fabp4, a late differentiation marker of adipogenesis and a representative target gene of C/ebp $\alpha$ and Ppary [32], was decreased in 3T3-L1 cells pretreated with dorsomorphin (Fig. 6C). These results suggest that endogenous Bmp activity prior to differentiation induction is responsible for adipocyte differentiation.

Our previous study indicated that the expression of Bmp4 was higher in preadipocytes and decreased after day 1 [12]. In view of the parallel changes in Bmp4 expression and the phosphorylation of Smad1/5/8, Bmp4 may be responsible for the higher Bmp activity before differentiation induction. The down-regulation of Bmp4 expression by transfection of cells with dsRNA for Bmp4 on day -3 to day 0 decreased lipid accumulation on day 8 (Fig. 7A and B). The treatment also decreased the expression of Ppary2, Clebpa and Fabp4 (Fig. 7C-E), suggesting that higher Bmp4 activity in preadipocytes is indispensable for adipocyte differentiation.

We further explored the molecular process regulated by Bmp4 in 3T3-L1 cells. The gene expression of molecules involved in adipocyte differentiation, including Zfp423, Interleukin-11, Pref-1 and lysyl oxidase (Lox), was examined. Zfp423 was identified as a gene highly expressed in fibroblasts committed to the adipocyte lineage and was found to be responsible for adipocyte differentiation [32]. Analysis of the nucleotide sequence from $-3 \mathrm{~kb}$ to the transcriptional initiation site of the Zfp 423 gene revealed 6 possible Bmp-responsive elements (BRE: GCCGnCGC) in Drosophila cells [34] and mammalian cells [35] in the region from nt -883 to $n t-800 ; 5$ of these BREs partially overlapped (Fig. 8A). Zfp423 transcription was not decreased by treatment with Bmp inhibitors, and Bmp4 addition did not increase the expression of Zfp423-luc, even when the possible BREs were isolated (Fig. 8A and B). Furthermore, treatment with dorsomorphin or dsRNA for Bmp4 did not significantly decrease Zfp423 expression (Fig. 8C). Thus, we concluded that Zfp423 is not a target gene for endogenous Bmp activity in preadipocytes. 
Interleukin-11 was cloned based on its inhibitory activity on the differentiation of 3T3-L1 preadipocytes [36]. The knockdown of Bmp4 significantly increased the expression of Interleukin-11 on day 0 and day 2 in 3T3-L1 cells (Fig. 9A). Pref-1 is highly expressed in preadipocytes, and down-regulation of the expression of Pref-1 triggers the progression of the adipogenic program [37-41]. Transfection with dsRNA for Bmp4 significantly decreased the expression of Pref- 1 on day 0 and day 2 (Fig. 9B). Lox was identified as a gene that mediates Bmp-induced commitment to the adipocyte lineage [6]. Transfection with dsRNA for Bmp4 did not decrease Lox expression (data not shown).

Our previous study revealed that endogenous Bmp activity in preadipocytes is required for lipid accumulation in adipocytes [12]. Here, we extend this information: higher expression of Bmp4 in preadipocytes is indispensable for adipocyte differentiation. Previous studies revealed that a number of molecules are involved in the regulation of adipocyte differentiation, and most of these studies evaluated effects of the factors by treating with differentiation inducers [2]. In contrast, little information is available on factors affecting preadipocytic properties. The present study indicates the importance of states prior to differentiation induction for adipocyte differentiation. The provided basic information potentially contributes to understanding the control of the number of adipocytes.

Treatment with Interleukin-11 inhibited the adipocyte differentiation of 3T3-L1 preadipocytes, irrespective of the down-regulation of Pref-1 expression [42]. In view of the well-defined role of Pref- 1 as an inhibitor of adipocyte differentiation [35, 37], these results suggest that Interleukin-11 negatively regulates adipogenesis in a Pref-1-independent manner. Bmp4 produced in preadipocytes may stimulate adipocyte differentiation through the repression of Interleukin-11 expression; the expression levels of Interleukin-11 and Pref-1 were increased and decreased, respectively, in 3T3-L1 cells with down-regulated Bmp4 expression.

The present study revealed that higher expression of Bmp4 is required for the progression of the adipogenic program in preadipocytes that are already committed to the adipogenic lineage. Previous studies indicated that Bmp4 stimulates the commitment of mesenchymal stem cells to the adipocyte lineage [5-7]. In conclusion, there are at least two roles of Bmp in adipocyte differentiation: a role in inducing the commitment of preadipocytes and a role in maintaining preadipocytic properties, as 
revealed in the present study.

\section{Acknowledgements}

We thank Dr. Peter ten Dijke for providing plasmid. This work was supported by Kakenhi from The Japan Society for the Promotion of Science.

\section{References}

[1] Rosen ED, Spiegelman BM. Adipocytes as regulators of energy balance and glucose homeostasis. Nature 2006; 444: 847-53.

[2] Tontonoz P, Spiegelman BM. Fat and beyond: the diverse biology of PPAR $\gamma$. Annu. Rev. Biochem. 2008; 77: 289-312.

[3] Chang H, Brown CW, Matzuk MM. Genetic analysis of the mammalian transforming growth factor- $\beta$ superfamily. Endocr. Rev. 2002; 23: 787-823.

[4] Otto TC, Lane MD. Adipose development: from stem cell to adipocyte. Crit. Rev. Biochem. Mol. Biol. 2005; 40: 229-42.

[5] Tang QQ, Otto TC, Lane MD. Commitment of C3H10T1/2 pluripotent stem cells to the adipocyte lineage. Proc. Natl. Acad. Sci. USA 2004; 101: 9607-11.

[6] Huang H, Song TJ, Li X, Hu L, He Q, Liu M, Lane MD, Tang QQ. BMP signaling pathway is required for commitment of C3H10T1/2 pluripotent stem cells to the adipocyte lineage. Proc. Natl. Acad. Sci. USA 2009; 106: 12670-5.

[7] Jin W, Takagi T, Kanesashi SN, Kurahashi T, Nomura T, Harada J, Ishii S. Schnurri-2 controls BMP-dependent adipogenesis via interaction with Smad proteins. Dev. Cell 2006; 10: 461-71.

[8] Bowers RR, Kim JW, Otto TC, Lane MD. Stable stem cell commitment to the adipocyte lineage by inhibition of DNA methylation: role of the BMP-4 gene. Proc. Natl. Acad. Sci. USA 2006; 103: 13022-7.

[9] Skillington J, Choy L, Derynck R. Bone morphogenetic protein and retinoic acid signaling cooperate to induce osteoblast differentiation of preadipocytes. J. Cell Biol. 2002; 159: 135-46.

[10] Rebbapragada A. Benchabane H. Wrana JL. Celeste AJ. Attisano L. Myostatin signals through a transforming growth factor $\beta$-like signaling pathway to block adipogenesis. Mol. Cell. Biol. 2003; 23: 7230-42.

[11] Lane MD, Tang QQ, Jiang MS. Role of the CCAAT enhancer binding proteins (C/EBPs) in adipocyte differentiation. Biochem. Biophys. Res. Commun. 1999; 
266: 677-83.

[12] Suenaga M, Matsui T, Funaba M. BMP Inhibition with dorsomorphin limits adipogenic potential of preadipocytes. J. Vet. Med. Sci. 2010; 72: 373-7.

[13] Hirai S, Matsumoto H, Hino N, Kawachi H, Matsui T, Yano H. Myostatin inhibits differentiation of bovine preadipocyte. Domest. Anim. Endocrinol. 2007; 32: 1-14.

[14] Yu PB, Hong CC, Sachidanandan C, Babitt JL, Deng DY, Hoyng SA, Lin HY, Bloch KD, Peterson RT. Dorsomorphin inhibits BMP signals required for embryogenesis and iron metabolism. Nat. Chem. Biol. 2008; 4: 33-41.

[15] Yu PB, Deng DY, Lai CS, Hong CC, Cuny GD, Bouxsein ML, Hong DW, McManus PM, Katagiri T, Sachidanandan C, Kamiya N, Fukuda T, Mishina Y, Peterson RT, Bloch KD. BMP type I receptor inhibition reduces heterotopic ossification. Nat. Med. 2008; 14: 1363-9.

[16] Labarca C, Paigen K. A simple, rapid, and sensitive DNA assay procedure. Anal. Biochem. 1980; 102: 344-52.

[17] Funaba M, Murakami M. A sensitive detection of phospho-Smad1/5/8 and Smad2 in Western blot analyses. J. Biochem. Biophys. Methods 2008; 70: 816-9.

[18] Murakami M. Kawachi H. Ogawa K. Nishino Y. Funaba M. Receptor expression modulates the specificity of transforming growth factor- $\beta$ signaling pathways. Genes Cells 2009; 14: 469-82.

[19] Feng XH, Derynck R. Specificity and versatility in TGF- $\beta$ signaling through Smads. Annu. Rev. Cell Dev. Biol. 2005; 21: 659-93.

[20] Miyazono K. Kamiya Y. Morikawa M. Bone morphogenetic protein receptors and signal transduction. J. Biochem. 2010; 147: 35-51.

[21] Cuny GD, Yu PB, Laha JK, Xing X, Liu JF, Lai CS, Deng DY, Sachidanandan C, Bloch KD, Peterson RT. Structure-activity relationship study of bone morphogenetic protein (BMP) signaling inhibitors. Bioorg. Med. Chem. Lett. 2008; 18: 4388-92.

[22] Goumans MJ, Valdimarsdottir G, Itoh S, Lebrin F, Larsson J, Mummery C, Karlsson S, ten Dijke P. Activin receptor-like kinase (ALK)1 is an antagonistic mediator of lateral TGFß/ALK5 signaling. Mol. Cell 2003; 12: 817-28.

[23] Daly AC, Randall RA, Hill CS. Transforming growth factor $\beta$-induced Smad1/5 phosphorylation in epithelial cells is mediated by novel receptor complexes and is essential for anchorage-independent growth. Mol. Cell. Biol. 2008; 28: 6889-902.

[24] Liu IM, Schilling SH, Knouse KA, Choy L. Derynck R. Wang XF. 
TGF $\beta$-stimulated Smad1/5 phosphorylation requires the ALK5 L45 loop and mediates the pro-migratory TGF $\beta$ switch. EMBO J. 2009; 28: 88-98.

[25] Wrighton KH, Lin X, Yu PB, Feng XH. Transforming growth factor $\beta$ can stimulate Smad1 phosphorylation independently of bone morphogenic protein receptors. J. Biol. Chem. 2009; 284: 9755-63.

[26] Korchynskyi O, ten Dijke P. Identification and functional characterization of distinct critically important bone morphogenetic protein-specific response elements in the Id1 promoter. J. Biol. Chem. 2002; 277: 4883-91.

[27] Zhou G, Myers R, Li Y, Chen Y, Shen X, Fenyk-Melody J, Wu M, Ventre J, Doebber T, Fujii N, Musi N, Hirshman MF, Goodyear LJ, Moller DE. Role of AMP-activated protein kinase in mechanism of metformin action. J. Clin. Invest. 2001; 108: 1167-74.

[28] Barak Y, Nelson MC, Ong ES, Jones YZ, Ruiz-Lozano P, Chien KR, Koder A, Evans RM. PPAR $\gamma$ is required for placental, cardiac, and adipose tissue development. Mol. Cell 1999; 4: 585-95.

[29] Kubota N, Terauchi Y, Miki H, Tamemoto H, Yamauchi T, Komeda K, Satoh S, Nakano R, Ishii C, Sugiyama T, Eto K, Tsubamoto Y, Okuno A, Murakami K, Sekihara H, Hasegawa G, Naito M, Toyoshima Y, Tanaka S, Shiota K, Kitamura T, Fujita T, Ezaki O, Aizawa S, Nagai R, Tobe K, Kumura S, Kadowaki T. PPAR $\gamma$ mediates high-fat diet-induced adipocyte hypertrophy and insulin resistance. Mol. Cell 1999; 4: 597-609.

[30] Rosen ED, Sarraf P. Troy AE. Bradwin G. Moore K. Milstone DS. Spiegelman $\mathrm{BM}$, Mortensen RM. PPAR $\gamma$ is required for the differentiation of adipose tissue in vivo and in vitro. Mol. Cell 1999; 4: 611-7.

[31] Wu Z, Rosen ED, Brun R, Hauser S, Adelmant G, Troy AE, McKeon C, Darlington GJ, Spiegelman BM. Cross-regulation of C/EBP $\alpha$ and PPAR $\gamma$ controls the transcriptional pathway of adipogenesis and insulin sensitivity. Mol. Cell 1999; 3: $151-8$.

[32] Tang QQ, Zhang JW, Lane MD. Sequential gene promoter interactions by $\mathrm{C} / \mathrm{EBP} \beta, \mathrm{C} / \mathrm{EBP} \alpha$, and PPAR $\gamma$ during adipogenesis. Biochem. Biophys. Res. Commun. 2004; 318: 213-8.

[33] Gupta RK, Arany Z, Seale P, Mepani RJ, Ye L, Conroe HM, Roby YA, Kulaga H, Reed RR, Spiegelman BM. Transcriptional control of preadipocyte determination by Zfp423. Nature 2010; 464: 619-23.

[34] Kim J, Johnson K, Chen HJ, Carroll S, Laughon A. Drosophila Mad binds to DNA and directly mediates activation of vestigial by Decapentaplegic. Nature 
1997; 388: 304-8.

[35] Kusanagi K, Inoue H, Ishidou Y, Mishima HK, Kawabata M, Miyazono K. Characterization of a bone morphogenetic protein-responsive Smad-binding element. Mol. Biol. Cell 2000; 11: 555-65.

[36] Kawashima I, Ohsumi J, Mita-Honjo K, Shimoda-Takano K, Ishikawa H, Sakakibara S, Miyadai K, Takiguchi Y. Molecular cloning of cDNA encoding adipogenesis inhibitory factor and identity with interleukin-11. FEBS Lett. 1991; 283: 199-202.

[37] Smas CM, Sul HS. Pref-1, a protein containing EGF-like repeats, inhibits adipocyte differentiation. Cell 1993; 73: 725-34.

[38] Smas CM, Kachinskas D, Liu CM, Xie X, Dircks LK, Sul HS. Transcriptional control of the pref-1 gene in 3T3-L1 adipocyte differentiation. Sequence requirement for differentiation-dependent suppression. J. Biol. Chem. 1998; 273: 31751-8.

[39] Smas CM, Chen L, Zhao L, Latasa MJ, Sul HS. Transcriptional repression of pref-1 by glucocorticoids promotes 3T3-L1 adipocyte differentiation. J. Biol. Chem. 1999; 274: 12632-41.

[40] Garcés C, Ruiz-Hidalgo MJ, Bonvini E, Goldstein J, Laborda J. Adipocyte differentiation is modulated by secreted delta-like (dlk) variants and requires the expression of membrane-associated dlk. Differentiation 1999; 64: 103-14.

[41] Wang Y, Sul HS. Pref-1 regulates mesenchymal cell commitment and differentiation through Sox9. Cell Metab. 2009; 9: 287-302.

[42] Boney CM, Fiedorek FT Jr, Paul SR, Gruppuso PA. Regulation of preadipocyte factor-1 gene expression during 3T3-L1 cell differentiation. Endocrinology 1996; 137: 2923-8. 


\section{Figure legends}

Fig. 1. Endogenous Bmp activity is higher prior to differentiation induction in 3T3-L1 cells

Phosphorylation status of Smad1/5/8 during adipocyte differentiation in 3T3-L1 and NIH-3T3 cells. 3T3-L1 and NIH-3T3 cells were stimulated with differentiation inducers for 2 days starting on day 0 . Samples containing $1 \mu \mathrm{g}$ of DNA were subjected to Western blotting to detect phosphorylated Smad1/5/8 at C-terminal serines (upper panel). The membranes were re-blotted with an antibody against Smad1 (middle panel) or $\beta$-actin (lower panel).

Fig. 2. Expression of Bmp receptors dynamically changes during adipogenesis in 3T3-L1 cells

Time-course changes in the gene expression of Alk2 (A), Alk3 (B), Actr2a (C), Actr2b (D) and Bmpr2 (E) during adipogenesis were examined by RT-qPCR analyses in 3T3-L1 cells. The gene transcript levels were examined on day -4, -2, -1, 0, 1, 2, 4, 6 and 8, and are expressed as ratios relative to Hprt1 expression, with the level in 3T3-L1 cells on day -4 set to 1 . Data are expressed as the mean \pm SE of quadruplicates.

Fig. 3. Endogenous Bmp activity prior to differentiation induction is required for efficient lipid accumulation in 3T3-L1 cells

(A) Smad phosphorylation in response to the Tgf- $\beta$ family in 3T3-L1 cells treated with dorsomorphin or LDN-193189. 3T3-L1 cells at 70\% confluence were pre-treated with dorsomorphin (DM: $5 \mu \mathrm{M})$, LDN-193189 (LDN: $100 \mathrm{nM})$ or DMSO as a vehicle control (V) for $20 \mathrm{~min}$, followed by treatment with Tgf- $\beta 1$ (200 pM), Activin A (4 nM) or Bmp2 (4 $\mathrm{nM}$ ) for $1 \mathrm{~h}$. Phosphorylated Smad1/5/8 (upper panel) and Smad2 (third panel) were examined by Western blotting, and the membranes were then re-blotted for total Smad1 (second panel) and Smad2 (fourth panel). (B) Effects of dorsomorphin and LDN-193189 on Bmp-mediated transcription. 3T3-L1 cells were transiently transfected with BRE-luc and Renilla-luc and treated with dorsomorphin (DM: $5 \mu \mathrm{M}$ ), LDN-193189 (LDN: $100 \mathrm{nM}$ ) or DMSO as a vehicle control (V) for $20 \mathrm{~min}$, followed by treatment with or without Bmp4 (4 nM) for $16 \mathrm{~h}$. Firefly luciferase activity was normalized to Renilla luciferase activity, and the luciferase activity in cell lysates in the absence of Bmp4 and inhibitors was set to 1. Data were expressed as the mean $\pm \mathrm{SE}$ of triplicates from a representative experiment. (C) Suppression of lipid accumulation by 
the inhibition of Bmp activity in 3T3-L1 cells. Dorsomorphin (DM: $5 \mu \mathrm{M}$ ), LDN-193189 (LDN: $100 \mathrm{nM}$ ) or DMSO as a vehicle control (V) was added to the culture medium from day -2 to day 0 , and lipid accumulation on day 8 was examined by Oil Red O staining (upper panel). After staining, the dye was extracted with 2-propanol, and the amount was quantified by measuring the absorbance at $510 \mathrm{~nm}$. The absorbance of the extracted dye from cells treated with vehicle was set to 100. Data are expressed as the mean \pm SE of quadruplicates. $* *: P<0.01$ vs. vehicle.

Fig. 4. Exogenous Bmp does not affect lipid accumulation in 3T3-L1 cells (A and B) Limited effect of exogenous Bmp on lipid accumulation in 3T3-L1 cells. Bmp2 (4 $\mathrm{nM}$ ) was added to the culture medium for the indicated period (A), and lipid accumulation on day 8 was examined by Oil Red $\mathrm{O}$ staining (B, upper panel). After staining, the dye was extracted with 2-propanol, and the amount was quantified by measuring the absorbance at $510 \mathrm{~nm}$. The absorbance of the extracted dye from cells treated with vehicle was set to 100 (B, lower panel). Data are expressed as the mean \pm SE of quadruplicates.

Fig. 5. Endogenous Bmp activity prior to differentiation induction is also required for lipid accumulation in bovine SV cells

(A) Phosphorylation status of Smad1/5/8 during adipocyte differentiation in bovine SV cells. Bovine SV cells were stimulated with differentiation inducers for 2 days starting on day 0 . Samples containing $1 \mu \mathrm{g}$ of DNA were subjected to Western blotting to detect Smad1/5/8 phosphorylated at C-terminal serines (upper panel). The membranes were re-blotted with an antibody against Smad1 (middle panel) or $\beta$-actin (lower panel). (B and C) Suppression of lipid accumulation by the inhibition of Bmp activity in bovine SV cells. Dorsomorphin $(5 \mu \mathrm{M})$ or DMSO as a vehicle control was added to the culture medium for the indicated period (B), and lipid accumulation on day 8 was examined by Oil Red O staining (C, upper panel). After staining, the dye was extracted with 2-propanol, and the amount was quantified by measuring the absorbance at $510 \mathrm{~nm}$. The absorbance of the extracted dye from cells treated with vehicle was set to $100(\mathrm{C}$, lower panel). Data are expressed as the mean \pm SE of quadruplicates. $*$ and $* *: P<0.05$ and 0.01 , respectively, vs. vehicle. 
Fig. 6. Inhibition of Bmp activity prior to differentiation induction inhibits adipocyte differentiation in 3T3-L1 cells

Effects of inhibition of Bmp activity prior to differentiation induction on adipocyte differentiation. Dorsomorphin $(5 \mu \mathrm{M})$ or DMSO as a vehicle control was added to the culture medium from day -2 to day 0. The gene transcript levels of Ppary2 (A), C/ebp $\alpha$ (B) and Fabp4 (C) on day 8 were measured by RT-qPCR and are expressed as ratios relative to Hprt1 expression, with the level in 3T3-L1 cells treated with vehicle set to 100. Data shown are the mean $\pm \operatorname{SE}(n=4)$. **: $P<0.01$ vs. control.

Fig. 7. Down-regulation of Bmp4 prior to differentiation is sufficient to inhibit adipocyte differentiation in 3T3-L1 cells

(A) The down-regulation of Bmp4 expression in 3T3-L1 cells. 3T3-L1 cells were transfected with dsRNA for Bmp4 or GFP on day -3. The gene transcript level of Bmp4 on day 0 was measured by RT-qPCR and expressed as a ratio relative to Hprt 1 expression, with the level in 3T3-L1 cells treated with dsRNA for GFP set to 100. Data shown are the mean \pm SE $(n=4)$. **: P $<0.01$ vs. GFP. (B) Suppression of lipid accumulation in 3T3-L1 cells transfected with dsRNA for Bmp4. 3T3-L1 cells were transfected with dsRNA for Bmp4 or GFP as a negative control on day -3 , and lipid accumulation on day 8 was examined by Oil Red O staining (upper panel). After staining, the dye was extracted with 2-propanol, and the amount was quantified by the measuring absorbance at $510 \mathrm{~nm}$. The absorbance of the extracted dye from cells treated with dsRNA for GFP was set to 100. Data are expressed as the mean $\pm \mathrm{SE}$ of quadruplicates. **: $\mathrm{P}<0.01$ vs. GFP. (C-E) Inhibition of adipocyte differentiation by knockdown of Bmp4. 3T3-L1 cells were transfected with dsRNA for Bmp4 or GFP on day -3. The gene transcript levels of Ppary2 (C), Clebp $\alpha$ (D) and Fabp4 (E) on day 8 were measured by RT-qPCR and expressed as ratios relative to Hprt1 expression, with the level in 3T3-L1 cells treated with dsRNA for GFP set to 100. Data shown are the mean $\pm \mathrm{SE}(n=4)$. **: $P<0.01$ vs. GFP.

Fig. 8. Zfp423 transcriptional regulation is independent of Bmp activity

(A) 3T3-L1 cells were transiently transfected with the indicated reporter gene and Renilla-luc and treated with or without Bmp4 (4 nM) for $16 \mathrm{~h}$. Firefly luciferase activity was normalized to Renilla luciferase activity, and the luciferase activity in cell lysates in the absence of inhibitors and Bmp4 was set to 1 . Data were expressed as the mean $\pm \mathrm{SE}$ 
of triplicates from a representative experiment. (B) 3T3-L1 cells were transiently transfected with Zfp423(-913)-luc and Renilla-luc and treated with dorsomorphin (5 $\mu \mathrm{M}), \mathrm{LDN}-193189$ (100 $\mathrm{nM})$ or DMSO as vehicle for $16 \mathrm{~h}$. (C) 3T3-L1 cells were transfected with dsRNA for Bmp4 or GFP on day -3. The gene transcript level of Zfp423 on day 8 was measured by RT-qPCR and expressed as a ratio relative to Hprt 1 expression, with the level in 3T3-L1 cells treated with dsRNA for GFP set to 100. Data shown are the mean $\pm \operatorname{SE}(n=4)$.

Fig. 9. Down-regulation of Bmp4 increases and decreases the expression of Interleukin-11 and Pref-1, respectively, in 3T3-L1 cells

Increased expression of Interleukin-11 (A) and decreased expression of Pref-1 (B) in response to the down-regulation of Bmp4 in 3T3-L1 cells. (A and B) 3T3-L1 cells were transfected with dsRNA for Bmp4 or GFP on day -3 . The gene transcript levels of Interleukin-11 (A) and Pref-1 (B) on day 0 and day 2 were measured by RT-qPCR and expressed as ratios relative to Hprt1 expression, with the level in 3T3-L1 cells treated with dsRNA for GFP set to 100. Data shown are the mean $\pm \operatorname{SE}(n=4) .{ }^{*}$ and $* *: P<$ 0.05 and 0.01 , respectively, vs. GFP. 
Table 1. Oligonucleotide PCR primers for RT-qPCR

\begin{tabular}{|c|c|c|c|}
\hline & \multicolumn{2}{|c|}{ Oligonucleotide } & \multirow{2}{*}{$\begin{array}{l}\text { GenBank } \\
\text { accession number }\end{array}$} \\
\hline & 5'-primer & 3'-primer & \\
\hline Actr2a & 5'CCCTCCTGTACTTGTTCCTACTCA-3' & 5'-GCAATGGCTTCAACCCTAGT-3' & M65287 \\
\hline Alk2 & 5’-AGGGCTCATCACCACCAAT-3' & 5'-GCCACTTCCTGATGTACACG-3' & L15436 \\
\hline Alk3 & 5'TGACCTGGGCCTAGCTGTTA-3' & 5'TTCAGGCTTTCATCCAGCA-3' & $\mathrm{Z} 23154$ \\
\hline $\mathrm{Bmp} 4$ & 5'-GAGGAGTTTCCATCACGAAGA-3' & 5’-GCTCTGCCGAGGAGATCA-3’ & NM_007554 \\
\hline Bmpr2 & 5'TGGGAGGTGTTTATGAGGTGT-3' & 5'GAAAAGCCATCTGGTAATCTGG-3' & $\mathrm{U} 78048$ \\
\hline Fabp4 & 5'AAGGTGAAGAGCATCATAACCCT-3' & 5'-TCACGCCTTTCATAACACATTCC-3' & NM_024406 \\
\hline Hprt1 & 5'-TCCTCCTCAGACCGCTTTT-3' & 5’-CCTGGTTCATCATCGCTAATC-3’ & NM_013556 \\
\hline Interleukin-11 & 5'-CGCCGTTTACAGCTCTTGA-3' & 5'-CAGGGGGATCACAGGTTG-3' & NM_008350 \\
\hline Lox & 5’-CAGGCTGCACAATTTCACC-3’ & 5'CAAACACCAGGTACGGCTTT-3’ & NM_010728 \\
\hline Ppary2 & 5'-TGCTGTTATGGGTGAAACTCTG-3' & 5'CTGTGTCAACCATGGTAATTTCTT-3' & NM_011146 \\
\hline Pref-1 & 5’-CGGGAAATTCTGCGAAATAG-3’ & 5'TGTGCAGGAGCATTCGTACT-3' & NM_010052 \\
\hline
\end{tabular}




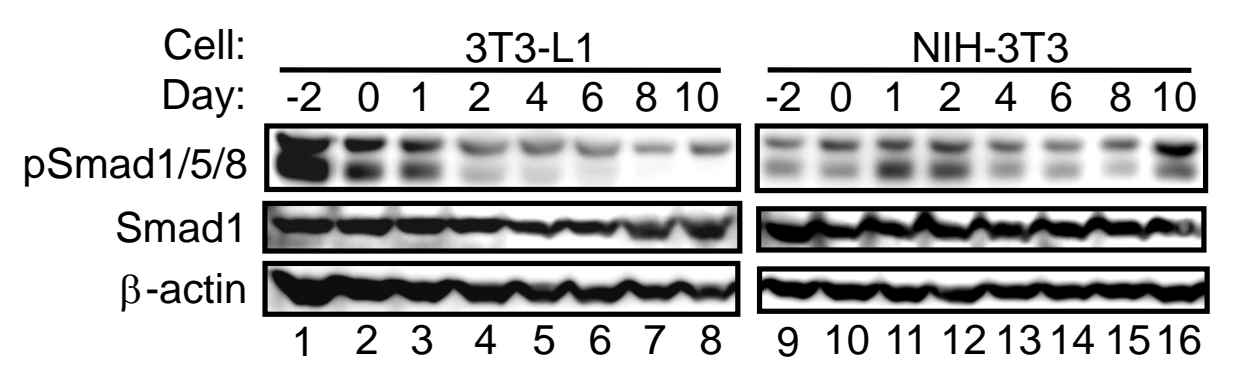


A

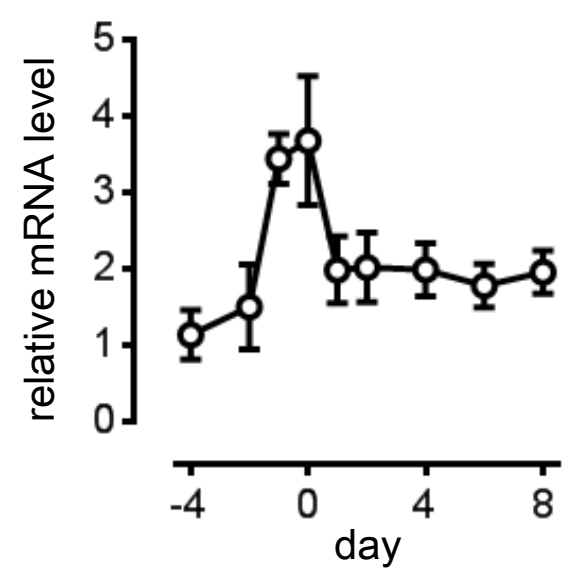

C

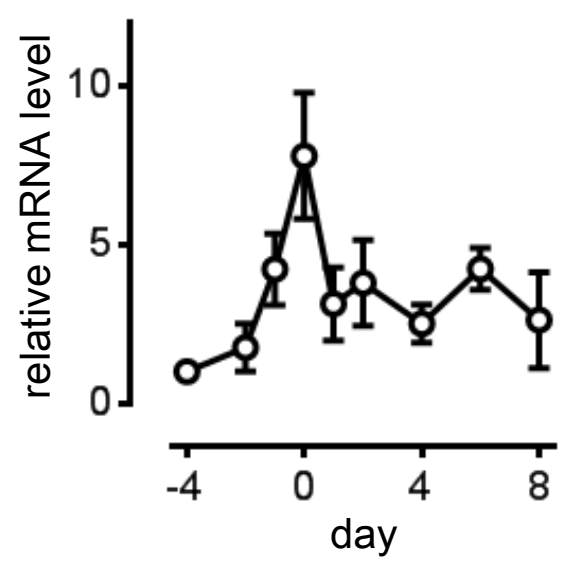

B Alk3

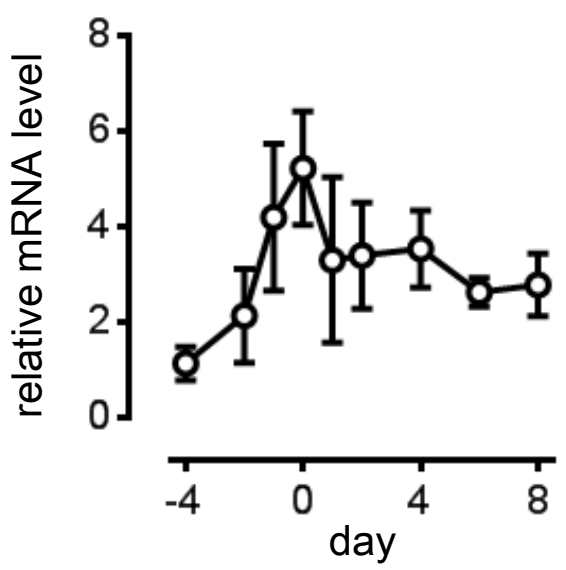

D

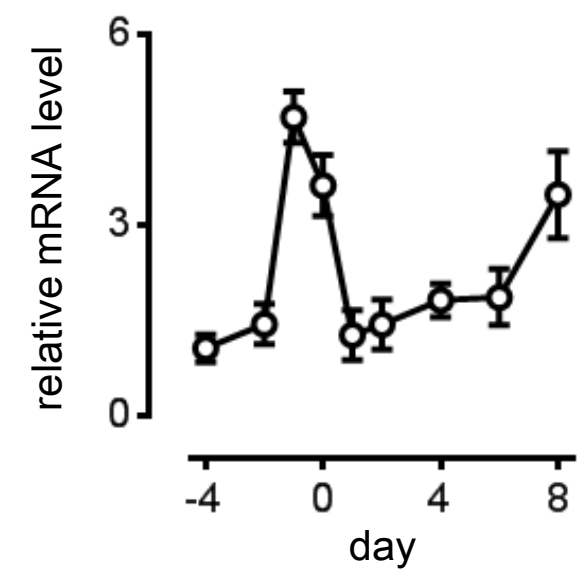

E Bmpr2

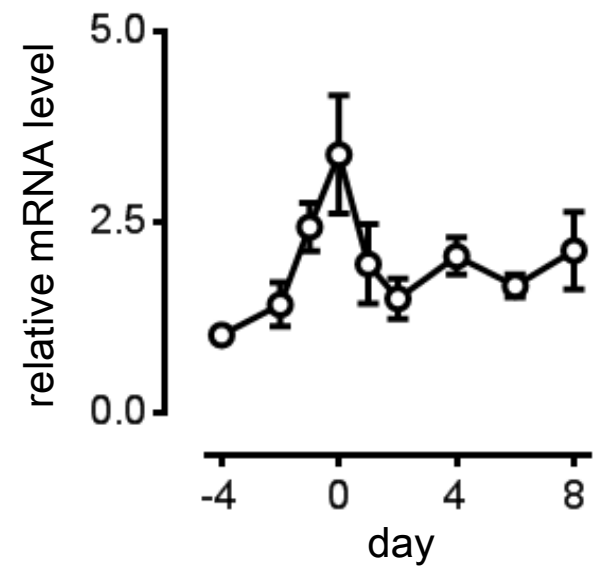


A

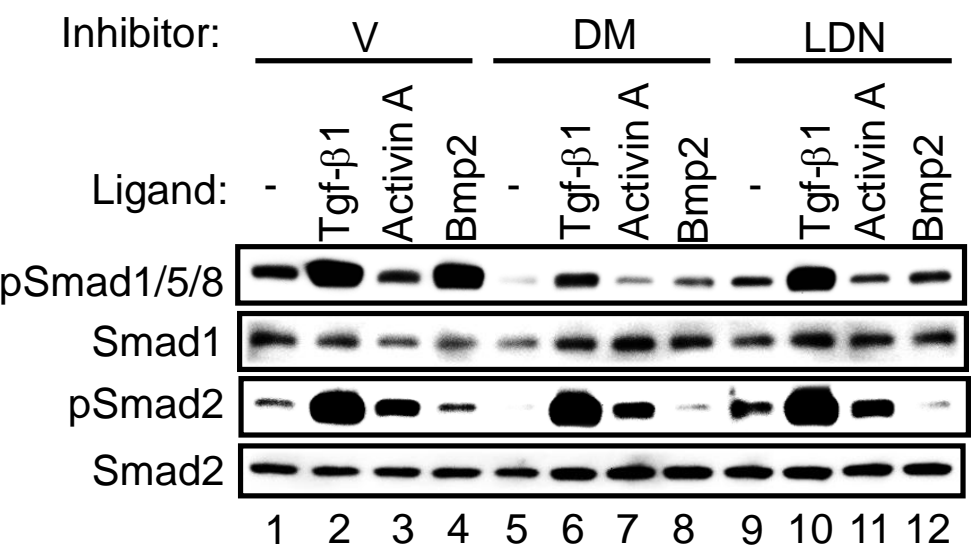

B

BRE-luc

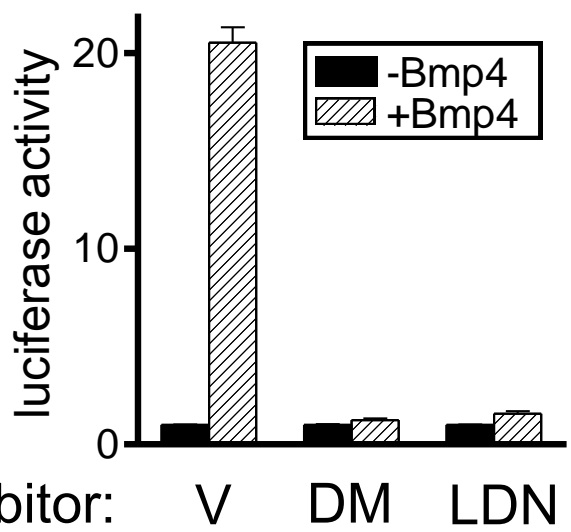

C

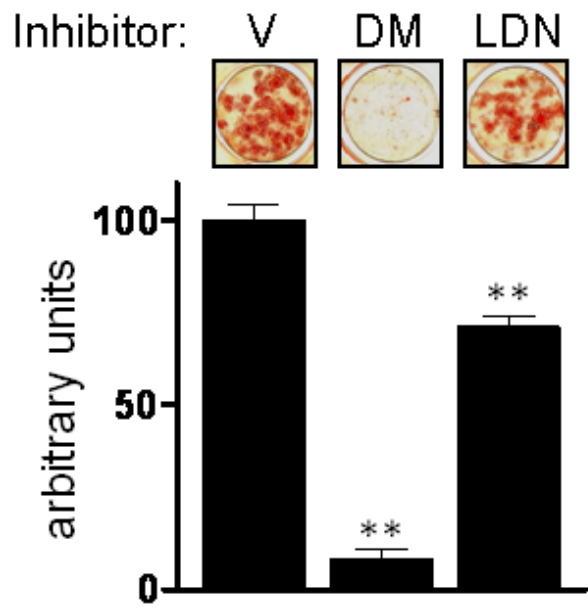


A

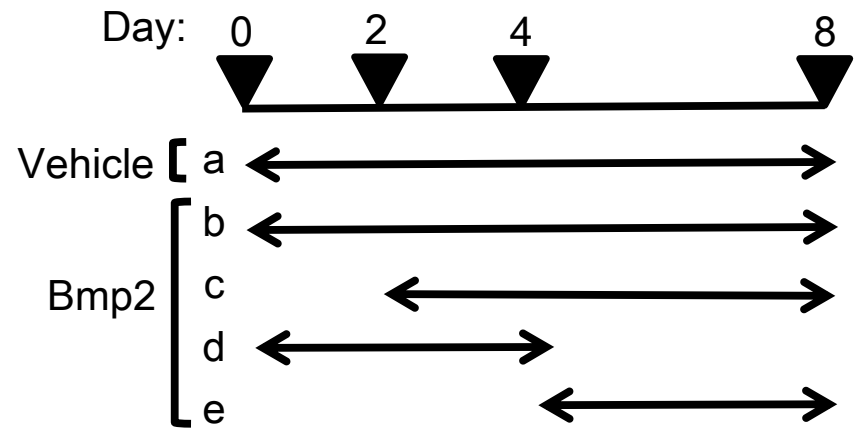

B

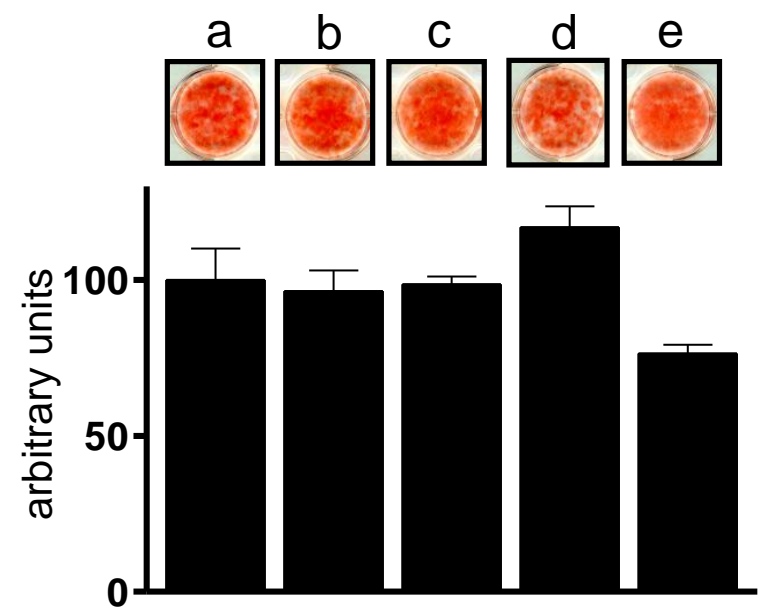




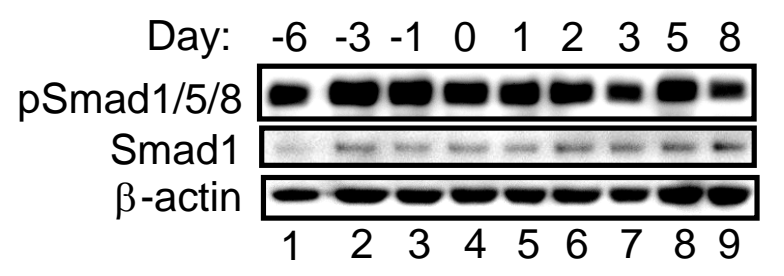

B
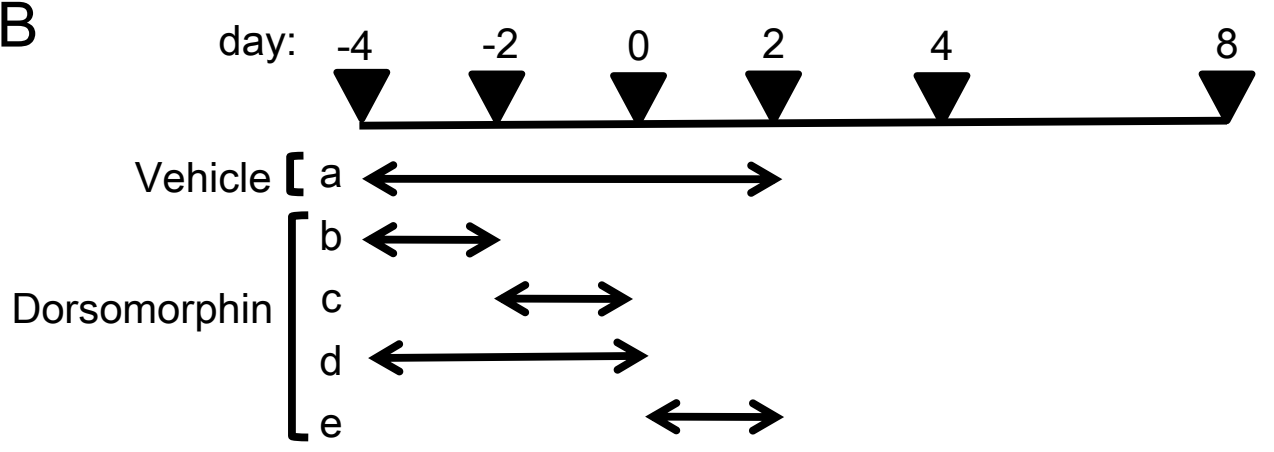

Vehicle [ $f$

Dorsomorphin [ $\mathrm{g}$

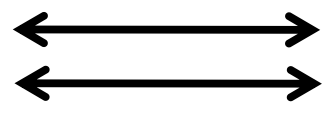

C

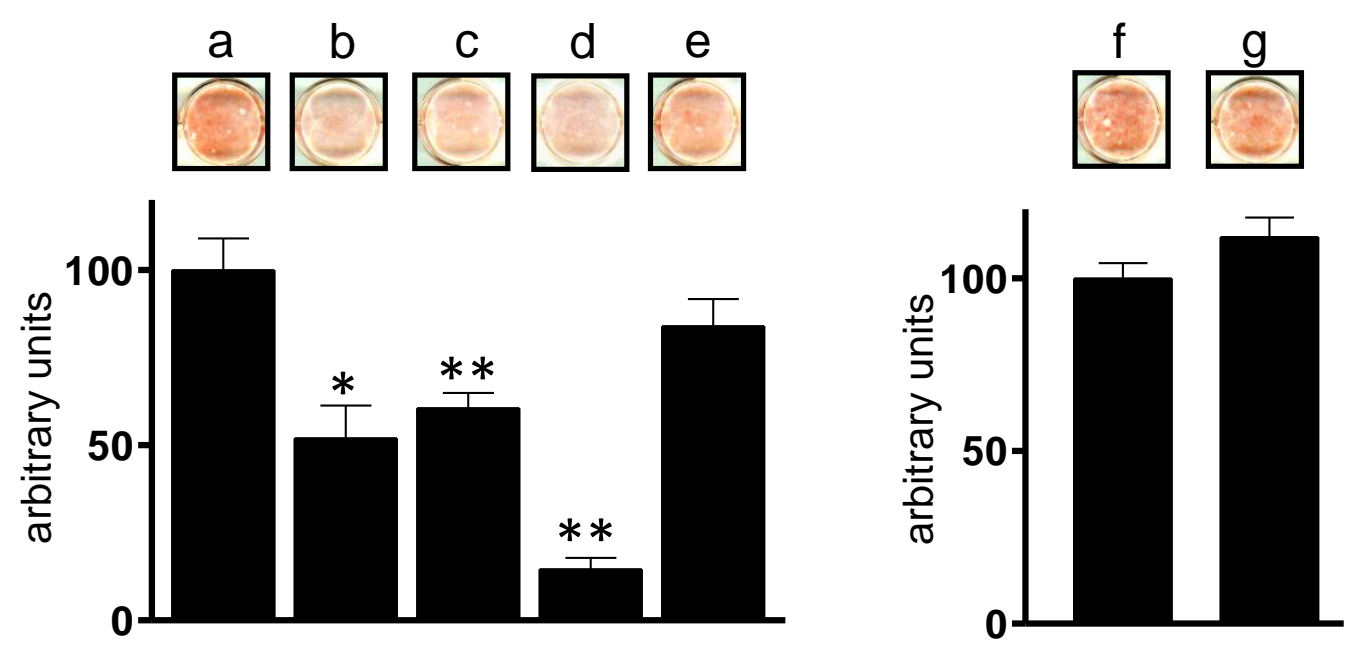




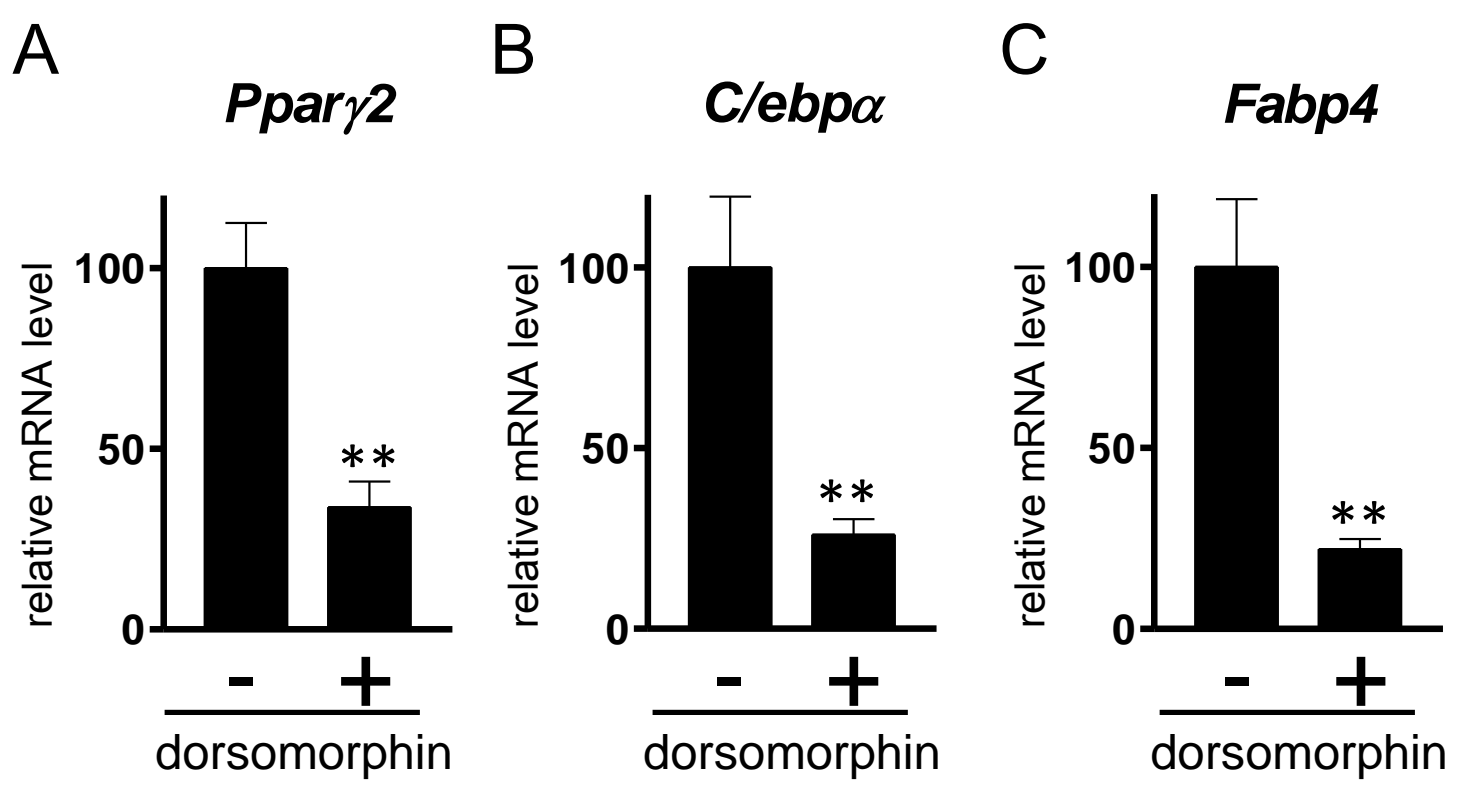


A B

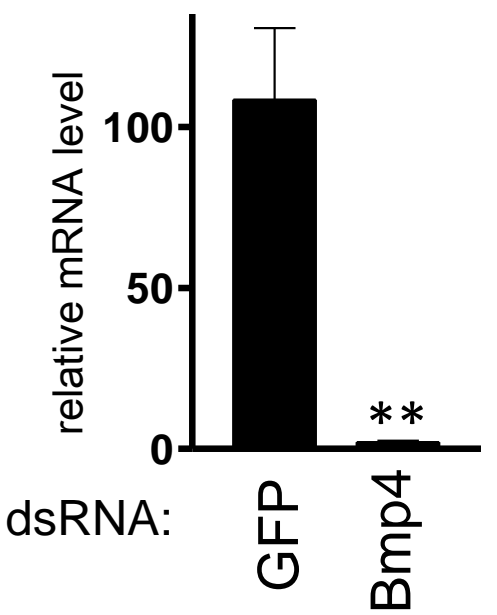

D clebpa

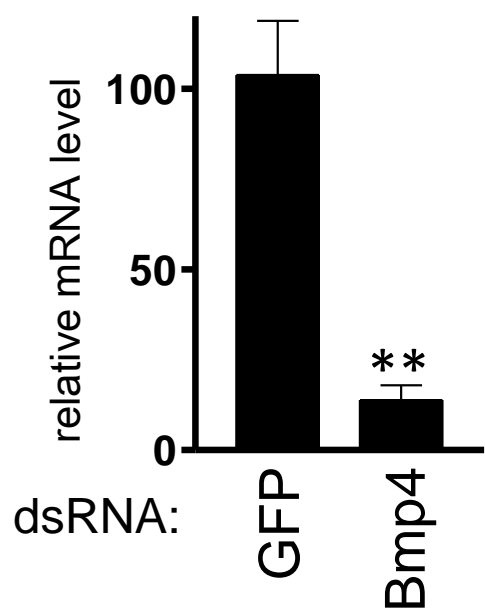

B

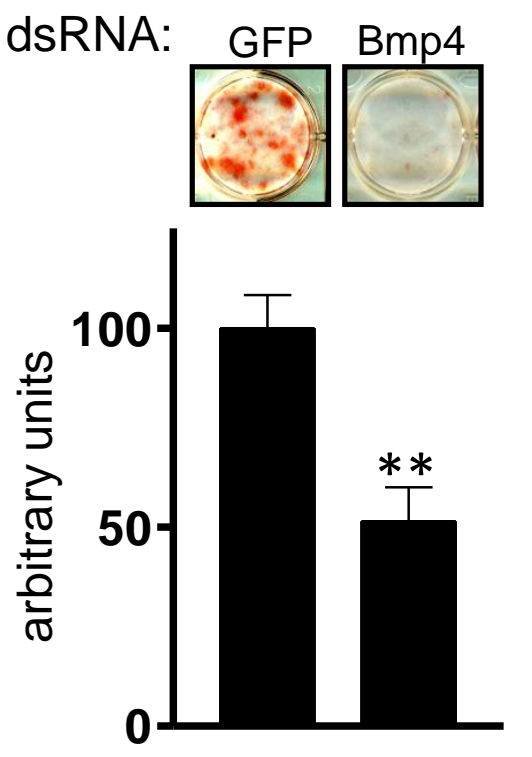

$E$

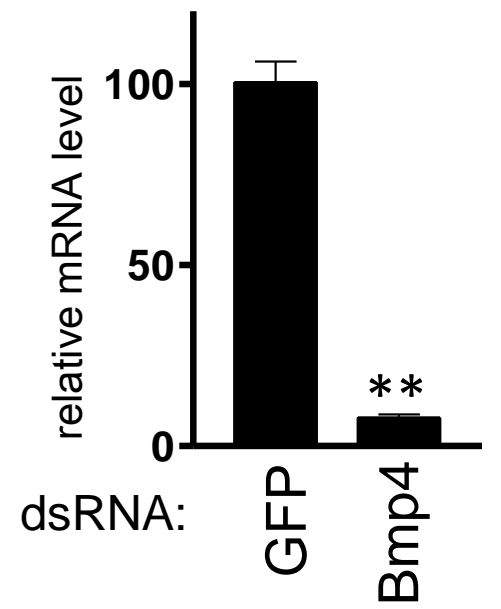

C

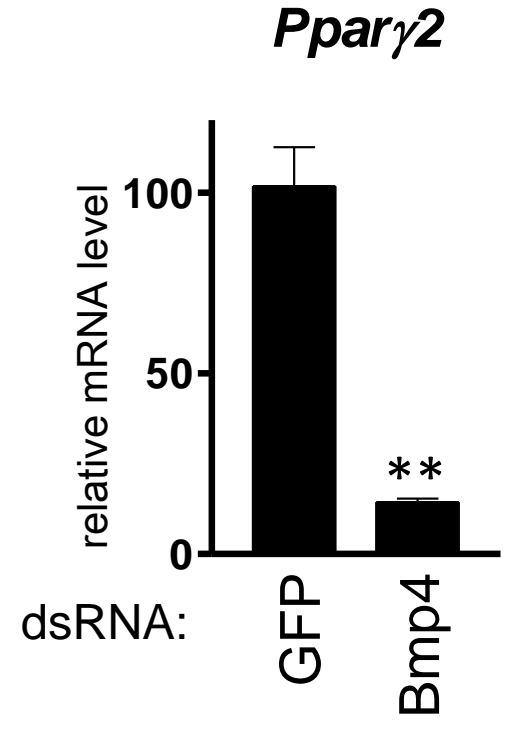




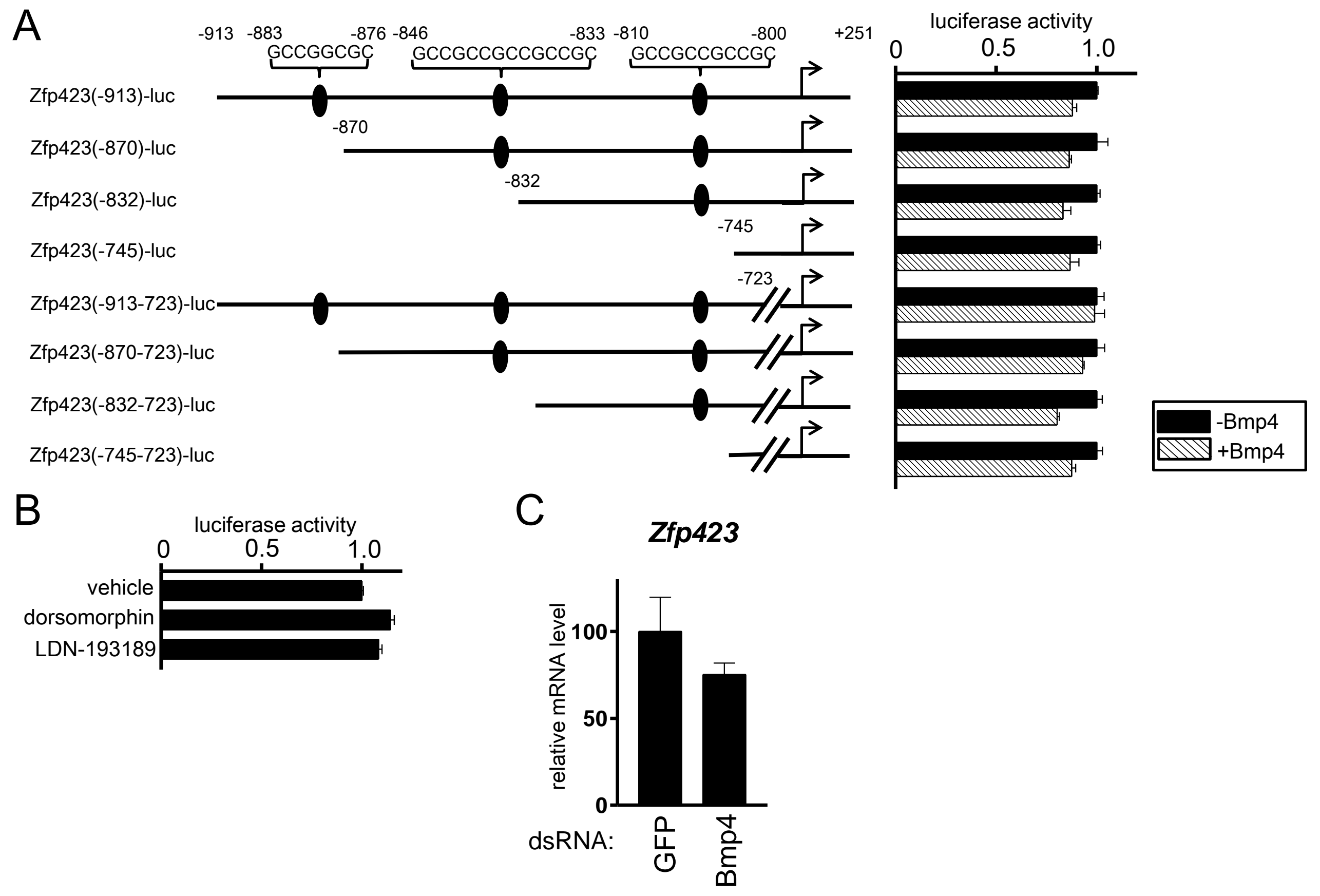


A

B

Interleukin-11

Pref-1
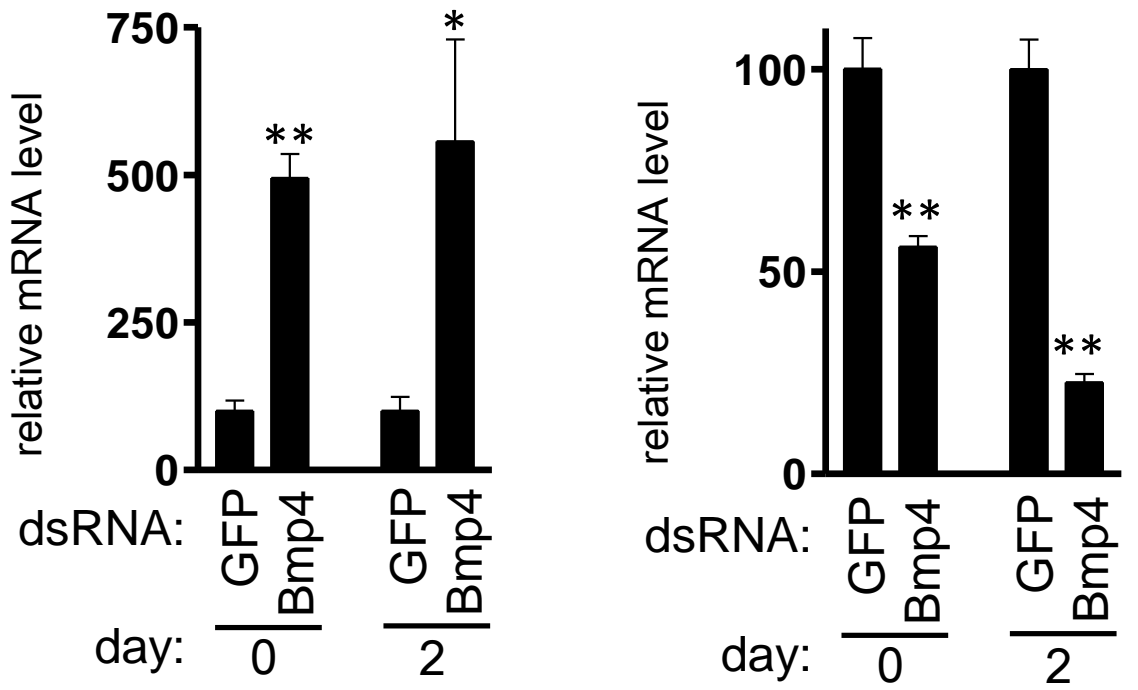